\title{
Global energy networks: Insights from headquarter subsidiary data of transnational petroleum corporations
}

\author{
Yu Yang a, Wen Dong a, b, * \\ a Institute of Geographic Sciences and Nature Resources Research, Chinese Academy of Sciences, Beijing 100101, China \\ ${ }^{\mathrm{b}}$ Xinjiang Institute of Ecology and Geography, Chinese Academy of Sciences, Urumqi 830011, China
}

\section{A R T I C L E I N F O}

\section{Article history:}

Received 29 July 2015

Received in revised form

30 April 2016

Accepted 14 May 2016

Available online 27 May 2016

\section{Keywords:}

Energy network

HQ subsidiary

International oil companies

National oil companies

\begin{abstract}
A B S T R A C T
Oil companies are powerful international actors, and have formed complex networks by building relationships from their headquarters (HQs) to subsidiaries. However, we do not know much about these networks as energy trade networks. In this paper, we select HQ subsidiary data of the most powerful oil companies in Fortune Global 500, and employ network analysis, Gini coefficient and Herfindahl index to investigate the network centrality, inequality and regional characteristics. We find that HQs are concentrated in the Unites States, Western Europe and East Asia while subsidiaries are more dispersed in both producing and consuming countries. Compared to the trade networks, HQ subsidiary network is more complex and displays greater inequality, especially in the out-degree network. IOCs (international oil companies) and NOCs (national oil companies) show different preferences for choosing subsidiaries locations and form different networks based on their industry value chains. A more complicated network including IOCs and NOCs will be more flexible in respond to market competition and geopolitical situation. HQ-subsidiary energy networks should be seriously considered along with the international diplomatic relations when making transnational energy policies and trading.
\end{abstract}

(C) 2016 Elsevier Ltd. All rights reserved.

\section{Introduction}

Due to an unbalanced geographical distribution of energy sources, especially fossil fuels, complex energy networks have been formed between energy suppliers and consumers. Many previous studies have focused on these energy networks, and the networks have been analyzed from many different angles. Some studies have examined the impact of oil networks from the perspective of oil demand. It has been found that diversification of oil imports was the key to ensuring the supply security of oil trade networks (Blum \& Legey, 2012; Vivoda, 2009; Yergin, 2006; Zhang, Ji, \& Fan, 2013). Some researchers have paid attention to crude oil suppliers, especially the strategy of the Organization of Petroleum Exporting Countries (OPEC). They have discussed whether OPEC could be characterized as the dominant power of crude oil trade networks (Alhajji \& Huettner, 2000a, 2000b; Bremond, Hache, \& Mignon, 2012; Cairns \& Calfucura, 2012; Dike, 2013; Kaufmann, 2004;

\footnotetext{
* Corresponding author. Institute of Geographic Sciences and Nature Resources Research, Chinese Academy of Sciences, Beijing 100101, China.

E-mail addresses: yangyu@igsnrr.ac.cn (Y. Yang), gucaswen@sina.com (W. Dong).
}

McGregor, 1979; Venouss, Walter, \& Thompson, 1984). In addition, the changes in global oil trade patterns caused by Russia, China, United States and other countries in Africa have been analyzed (Bin, 2014; Frynas \& Paulo, 2007; Leverett \& Bader, 2005; Mann, 2009; Watkins, 2009). Recently, complex network theory has been introduced into the research of crude oil trade to analyze global oil trade networks and their patterns (Geng, Ji, \& Fan, 2014; Ji, Zhang, \& Fan, 2014; Zhong, An, Gao, \& Sun, 2014). Global oil trade networks have been built and their characteristics identified by dividing the world into seven areas. It was found that geopolitics and diplomatic relations were the primary factors in the structure of the oil trade network. The characteristics of an importing-based network and an exporting-based network by whole network analysis were compared, and it was pointed out that oil trade networks were evolving into stable, orderly integrated systems (An, Zhong, Chen, Li, \& Gao, 2014; Ji et al., 2014; Zhang, Ji, \& Fan, 2014; Zhong et al., 2014; Yang, Poon, Liu, \& Sharmistha, 2015).

However, oil companies, especially transnational petroleum corporations, should never be ignored when analyzing global energy trade and business. They are the most significant actors in the global energy market, with monopolies in oil and gas reserves, exploration, refinery, and even the petrochemical industry and 
energy trade. Abundant previous research into oil companies has mainly focused on analysis of their management structure, profitability and growth (Knapp, 2004), financial performance (Pirog, 2012), and the strategic responses of major energy actors (Casertano, 2013). The responses to the local market (Ngoasong, 2014) and the role and competition of transnational companies in some special markets (Boussena \& Locatelli, 2013; Palazuelos \& Fernández, 2012; Palazuelos, 2010) have also been examined.

With the decline of international oil companies (IOCs), which occupy less than 10 percent of today's oil and gas reserves, national oil companies (NOCs) are receiving attention because of their approximately 90 percent share of world oil reserves and 75 percent share of world oil production, and because of their excellent performance in the international oil and gas capital markets (Tordo, Tracy, \& Arfaa, 2011). Some studies have focused on NOCs' exploration and development activities, while others have focused on operational efficiency (Hartley \& Medlock, 2008; 2013). Chinese NOCs are particularly noticeable for their national policies, their threat to the energy market, and their performance in capital markets (Feng \& Mu, 2010; Lewis, 2007; Zhang, 2012). Some comparative studies between the different development histories, policies, strategies and social responsibilities of NOCs and IOCs have been carried out (Pegg, 2012; Stevens, 2008).

As many oil companies are business empires and are very powerful, some have formed their own networks by setting up subsidiaries throughout the world. Different headquarter (HQ) subsidiary networks of oil companies constitute extremely global energy networks. This type of network is even more complex than energy trade network because it combines upstream and downstream businesses. How do these networks form? Do they share the same characteristics as energy trade networks? We currently know little about the answers to these questions. It is very important and valuable to construct such networks and to capture their characteristics to enhance our understanding of energy flows. HQsubsidiary analysis will provide a new perspective to previous studies and make a specific contribution to the existing trade networks (Poon, Kedron, \& Bagchi-Sen, 2013). In the next section, major network measures are outlined and described, which is followed by an analysis of HQ subsidiary network and its characteristics. After that, differences between HQ subsidiary networks and energy trade networks and those between IOCs networks and NOCs networks will be discussed.

\section{Methods and data}

\subsection{Network construction}

Network analysis has gained popularity because of its ability to represent the connections through the organization of spatial attributes (Benenson, Sofer, \& Schnell, 1998; Barigozzi, Fagiolo, \& Garlaschelli, 2010). Applying network model allows us to examine interconnections building by HQs between countries (Costa, Rodrigues, Travieso, \& Boas, 2007). Integrating GIS with networks facilitates the geo-visualization of HQ-subsidiaries in graphical representations, and provides a powerful means to better understand the structure (Singleton \& Longley, 2009).

Under a complex network model, relationships between HQs and their subsidiaries may be graphically captured by a collection of nodes and edges or links. Networks can be directed or nondirected. In non-directed networks, HQs and their subsidiaries are indistinguishable in a dyad, and edge direction is of little interest. In the case of a directed network, an oil company's HQ in country A sets up subsidiaries in country $B$, but there may not be such HQ-subsidiary relationships from country B to country A. The data indicate that HQs and subsidiaries are better captured in directed networks. The HQ subsidiary directed network may be represented by a set $G=(V, E)$, where the countries $V=\left\{v_{1}, v_{2}, \cdots, v_{n}\right\}$ are nodes and $E=\left\{\mathrm{e}_{i j}\right\}$ are edges of $\mathrm{HQ}$-subsidiary relationships. The network structure is described by an adjacent matrix $\mathrm{e}_{i j}=1$ if HQ-subsidiary relationships exist from country $v_{i}$ to country $v_{j}$; otherwise $\mathrm{e}_{i j}=0$.

$$
G=\left[\begin{array}{ccc}
e_{11} & \cdots & e_{1 m} \\
\vdots & \ddots & \vdots \\
e_{n 1} & \cdots & e_{n m}
\end{array}\right]
$$

\subsection{Network centrality}

Following (Wasserma \& Faust, 1994), a diagraph consists of a set of nodes that represents the countries, and a set of connections or edges. For each edge, a relationship directionally exists from country $i$ to country $j$. Centrality measures may be generated by analyzing the degree $(k)$ of the country node. Degree refers to the extent that two nodes are graphically adjacent (i.e. connected) to one another and hence serves as a local point-based centrality measure (Scott, 2000). In effect, $k$ measures the number of edges in an unweighted matrix. A country with a higher $k$ commands a more important structural position because it has many direct linkages with countries. In other words, the country is characterized by a larger neighborhood and is more centrally located. Total nodal degree $k$ may be further divided into in-degree $k_{j}^{\text {in }}$ (subsidiary country node) and out-degree $k_{i}^{\text {out }}$ (HQ country node).

$k_{j}^{\text {in }}=\sum_{i=1}^{N} e_{j i}, k_{i}^{\text {out }}=\sum_{j=1}^{N} e_{i j}$

where $k_{i}^{\text {in }}$ is the number of edges to a country, $k_{i}^{\text {out }}$ is the number of edges from a country and $e$ is an element of $E$.

\subsection{Measures of equality}

We create a Lorenz curve and a Gini coefficient, which are commonly used to measure the inequality degree of the social distribution of income in economics, to measure the equality of the HQ subsidiary network. The Lorenz curve is the simulation of the cumulative distribution of the nodes, represented by function $Y=L$ (x). Gini can be calculated as formula (3).

Gini $=1-2 \int_{0}^{1} L(x) d x$

where Gini $\in[0,1]$; 0 means perfect equality, while 1 means perfect inequality.

As a controversial index, Gini coefficient is simple and relative. This simplicity can lead to oversights occasionally and cannot interpret the inner structure. Here, we only use it to explain the general status of network equality. We introduce Herfindahl index (also known as Herfindahl-Hirschman Index, or HHI) to analyze the concentration and dispersion. HHI can be calculated as formula (4).

$\mathrm{HHI}=\sum_{i=1}^{N}\left(\mathrm{x}_{i} / \mathrm{X}\right)^{2}=\sum_{i=1}^{N}\left(\mathrm{~s}_{i}\right)^{2}$

where $\mathrm{x}_{i}$ is the degree, in-degree or out-degree of a given country. $\mathrm{X}$ is the total degree, in-degree and out-degree of all countries. $s_{i}$ 
represents the share of country $\mathrm{i}$. HHI ranges from $1 / \mathrm{N}$ to 1 . A low $\mathrm{HHI}$ value very close to $1 / \mathrm{N}$ indicates high dispersion, while a high $\mathrm{HHI}$ value indicates high concentration.

\subsection{Data and materials}

In order to collect the representative HQ subsidiary data of international petroleum corporations, we chose the oil and gas companies listed in Fortune Global 500. As there are no unique statistical standards for each company to publish related information on their websites or in their annual reports, the data in this paper are incomplete statistical data. Only the energy companies listed in the Fortune Global 500 that have international subsidiaries are studied; Mexican Petroleums, PDVSA (Venezuelan NOC) and ECOPETROL (Empresa Colombiana de Petróleos S.A.), ranked 12, 13 and 30 in Global 500, are not included because we cannot find their actual overseas subsidiaries. In addition, in attempting to describe the general networks, we assume that all the records are homogeneous. This may lead to a little distortion to some extent. Some subsidiaries have more assets and finance supports than others, so they may play more important roles in the networks. Although because of the restrictions on obtaining financial information of each subsidiary, this assumption is still helpful in building the initial networks.

A great deal of previous research has focused on oil and gas flows in which to analyze global energy networks based on complex network theory (see Section 1). We would therefore like to make a comparative study between an HQ subsidiary network and a trade network. Here, we obtained oil flow data from the United Nations trade database and the pickup commodity code HS 2709, which indexes petroleum oils, oils from bituminous minerals, and crude oil.

\section{Results and discussion}

\subsection{Summary statistics}

Data for 33 transnational petroleum corporations are shown in Table 1, including IOCs and NOCs as well as some private oil companies. There are 162 nodes and 918 links in the global energy network based on the HQ subsidiary data. It can be seen that most of the HQs are concentrated in three types of countries. One type is the large developed consumers that have high levels of industrialization. Some of the countries are oil-producers, such as the US and UK. Some are heavily dependent on oil, such as Italy, Japan, South Korea and France. The second type is the newly industrialized countries with increased oil consumption due to their industrialization process, for example, China, Brazil, India and Thailand. The third type is oil-producing countries such as Russia, Norway and the United Arab Emirates, who use oil for their financial support. HQs are unevenly distributed across countries. The United States and China are ranked first, with five HQs each. Russia and India follow with three HQs. Other countries usually have one or two HQs.

With regard to transnational petroleum corporations, Shell is a global energy group with around 94,000 employees and about US\$ 460 billion in revenues, US\$ 164 billion in profits, US\$ 358 billion in assets in 97 countries and territories, and has the highest number of subsidiaries of all the oil companies listed. ENI, PETRONAS, Exxon Mobil, Total and BP also have widely distributed subsidiaries in more than 50 countries. It should be noted that China's NOCs, Sinopec and CNPC, are ranked second and third because of their great financial performance achieved with only 21 and 22 overseas subsidiaries, respectively. Generally speaking, the number of subsidiaries is a good index to reflect networks other than revenues.
NOCs are enterprises operated by the central government and monopolize the independent markets of the host country; however, IOCs make profits all over the world (see Section 3.4).

\subsection{Centrality analysis}

We have presented a map of the HQ subsidiary network based on degree and the actual relationships in Fig. 1. The sketch map depicts the main network with the most important and powerful oil companies by different scales of nodes (a larger size indicates a higher degree) and lines (HQ-subsidiary relationships). Most countries throughout the world are enrolled in the complicated network. Netherlands, United States, Italy, Russia, China, United Kingdom, Malaysia, France, United Arab Emirates and Norway are the top ten in terms of degree, and constitute the framework of the network. These countries comprise the hubs, and wide relationships radiate from the hubs to subsidiary countries. The hubs are concentrated in North America, Western Europe and Asia. It is noticeable that the United Arab Emirates is the only Gulf country occupying a significant position in the HQ subsidiary network, with its facilities widely dispersed in Western Europe, the United States, and the Middle East, thus creating a bridge between the Middle East and consumption countries.

To be specific, we list the top ten countries in terms of degree in Table 2. Seven of them consist of developed countries in Europe, and North America. The Netherlands has the highest degree $(k=107)$, followed by the United States $(k=92)$, Italy $(k=85)$, Russia $(k=71)$, United Kingdom $(k=66)$ and France $(k=63)$. These countries have subsidiary relationships in more than 50 countries, and have had a wide influence on the energy market for hundreds of years since the Industrial Revolution and First World War. There are five Asian countries in the top 20: China $(k=71)$, Malaysia $(k=66)$, India $(k=35)$, Thailand $(k=21)$ and Indonesia $(k=20)$. These countries are experiencing huge oil demands.

It is noteworthy that in the HQ subsidiary network, the degree of the oil-producers in the Middle East, Central Asia and Africa is not significant because they do not have many powerful transnational corporations to operate their businesses throughout the world. Only three producers, Brazil $(k=36)$, United Arab Emirates $(k=45)$ and Venezuela $(k=16)$, appear on the list. Their main energy businesses are deals made by NOCs domestically with trading partners, by the subsidiaries of the IOCs or by foreign NOCs directly. In addition, most of the producers in the Middle East, Africa, Central Asia and South America do not have enough capability to conduct downstream business with the main consumers. This means they are not able to set up international subsidiaries. This indicates that oil producer countries are losing their dominant position in the powerful HQ subsidiary network. Even the main members of the most powerful organization, OPEC, which once dominated the global oil export markets, are in a passive situation in the HQ subsidiary network.

There are significant differences between in-degree and outdegree. HHI index of in-degree is only 0.01 according to the formula (4). It indicates that in-degree generally represent a dispersion status. HHI index of out-degree is 0.07 which is 7 times of indegree, indicating that out-degree networks view shows much more concentration. In Fig. 2, we have shown in-degree and outdegree distribution to gain an insight into the network structure.

The out-degree and degree distributions have much in common, which means that they are most likely concentrated in several hub countries. Out-degree is dependent on the transnational corporation HQs, which can reflect the capability to control the resources reserves, operate the markets and master advanced technologies in the network to some extent. The IOCs from developed countries have dominated oil exploration and the global oil market for a long 
Table 1

HQ subsidiaries of energy companies in the Fortune Global 500.

\begin{tabular}{|c|c|c|c|c|}
\hline Rank & Name (abbreviation) & HQ country & Number of subsidiary countries & Rank in fortune global 500 \\
\hline 1 & Shell & Netherlands & 97 & 2 \\
\hline 2 & China Petrochemical Corporation (Sinopec) & China & 21 & 3 \\
\hline 3 & China National Petroleum Corporation (CNPC) & China & 22 & 4 \\
\hline 4 & Exxon Mobil & United States & 55 & 5 \\
\hline 5 & British Petroleum (BP) & United Kingdom & 52 & 6 \\
\hline 6 & Total & France & 55 & 11 \\
\hline 7 & Chevron & United States & 35 & 12 \\
\hline 8 & Gazprom & Russia & 45 & 17 \\
\hline 9 & ENI & Italy & 77 & 22 \\
\hline 10 & Petrobras & Brazil & 23 & 28 \\
\hline 11 & Lukoil & Russia & 34 & 43 \\
\hline 12 & Rosneft Oil & Russia & 17 & 46 \\
\hline 13 & Statoil & Norway & 34 & 54 \\
\hline 14 & Petroliam Nasional Berhad (PETRONAS) & Malaysia & 59 & 69 \\
\hline 15 & China National Offshore Oil (CNOOC) & China & 44 & 79 \\
\hline 16 & Marathon Petroleum (MPC) & United States & 8 & 81 \\
\hline 17 & Petroleum Authority of Thailand (PTT) & Thailand & 13 & 84 \\
\hline 18 & Indian Oil & India & 19 & 96 \\
\hline 19 & Pertamina & Indonesia & 8 & 123 \\
\hline 20 & Conocophillips & United States & 22 & 167 \\
\hline 21 & OMV Group & Austria & 33 & 179 \\
\hline 22 & International Petroleum Investment (IPIC) & United Arab Emirates & 33 & 207 \\
\hline 23 & Bharat Petroleum (BHARAT) & India & 5 & 242 \\
\hline 24 & Suncor Energy (SUNCOR) & Canada & 4 & 282 \\
\hline 25 & CPC Corporation, Taiwan (CPC) & China & 10 & 300 \\
\hline 26 & Pkn Orlen Group (PKN ORLEN) & Poland & 4 & 323 \\
\hline 27 & Korea Gas (KOGAS) & South Korea & 18 & 340 \\
\hline 28 & Gas Natural Fenosa & Spain & 26 & 360 \\
\hline 29 & Gasterra & Netherlands & 6 & 373 \\
\hline 30 & Cosmo Oil & Japan & 9 & 400 \\
\hline 31 & Oil \& Natural Gas (ONGC) & India & 11 & 424 \\
\hline 32 & Shaanxi Yanchang Petroleum (YCPC) & China & 4 & 432 \\
\hline 33 & Occidental Petroleum (OXY) & United States & 9 & 467 \\
\hline
\end{tabular}

Source: http://fortune.com/global500/

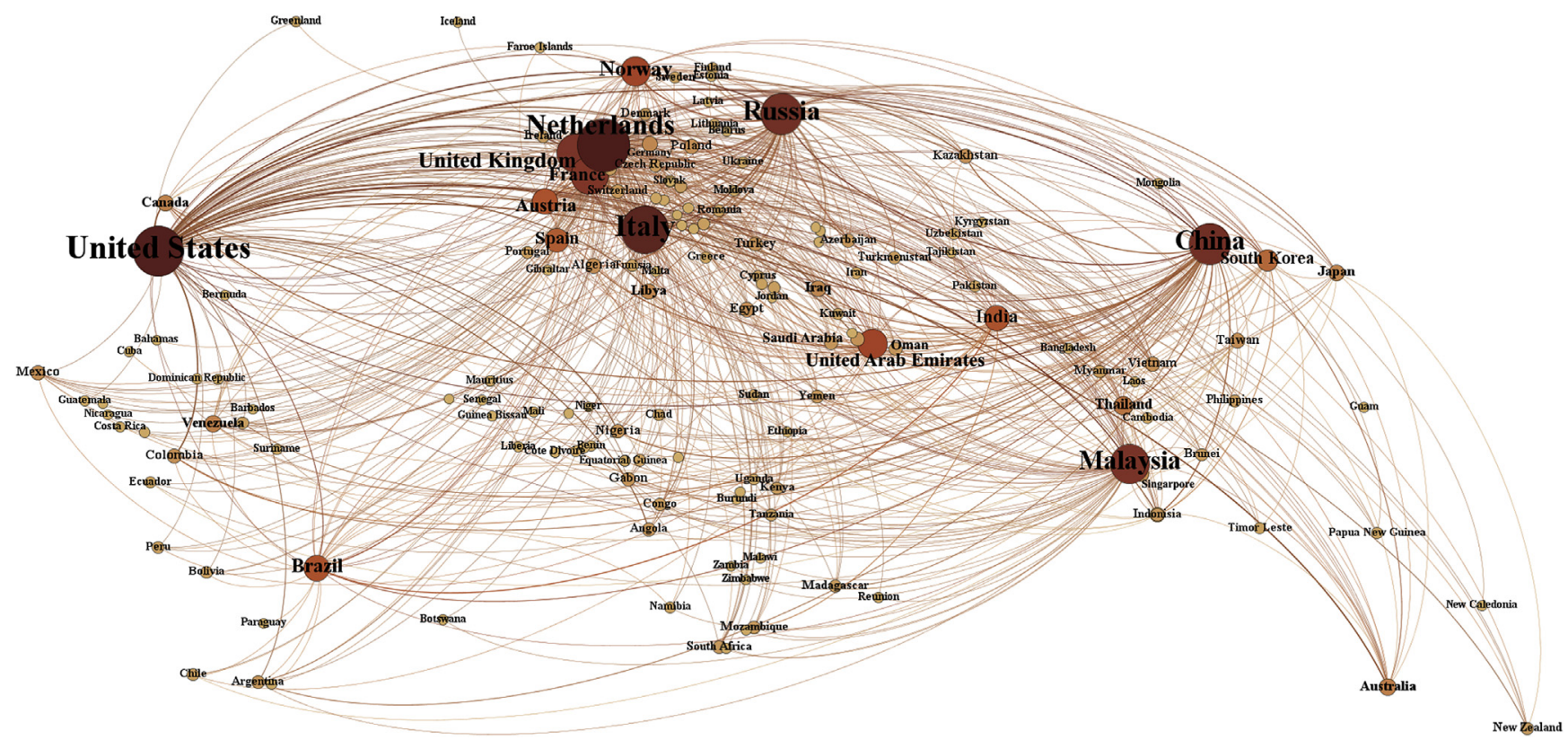

Fig. 1. Degree distribution of the global energy network based on HQ subsidiaries. Note: Node size captures k size while lines represent the HQ-subsidiary relationship.

time. Now, most countries that occupy the highest out-degrees still benefit from their huge assets that are widely distributed across the world.

The in-degree distribution is more dispersed and presents a very different spatial pattern from that of degree and out-degree. The most significant differences are in the Middle East and African countries, which are very unimpressive in the degree distribution but which are booming in the in-degree network. The distribution of subsidiaries is not as concentrated as the out-degree, which indicates that many powerful HQs are willing to incorporate 
Table 2

Degree, in-degree and out-degree of top ten countries.

\begin{tabular}{|c|c|c|c|c|c|c|}
\hline \multirow[t]{2}{*}{ Rank } & \multicolumn{2}{|l|}{ Degree $(\mathrm{k})$} & \multicolumn{2}{|l|}{ In-degree $\left(k_{\text {in }}\right)$} & \multicolumn{2}{|l|}{ Out-degree $\left(\mathrm{k}_{\text {out }}\right)$} \\
\hline & Country & Value & Country & Value & Country & Value \\
\hline 1 & Netherlands & 107 & Australia & 16 & Netherlands & 96 \\
\hline 2 & United States & 92 & United Kingdom & 14 & United States & 79 \\
\hline 3 & Italy & 85 & United States & 13 & Italy & 75 \\
\hline 4 & Russia & 71 & China & 13 & Russia & 61 \\
\hline 5 & China & 71 & United Arab Emirates & 13 & Malaysia & 59 \\
\hline 6 & United Kingdom & 66 & Brazil & 13 & China & 58 \\
\hline 7 & Malaysia & 66 & Germany & 13 & France & 55 \\
\hline 8 & France & 63 & Iraq & 13 & United Kingdom & 52 \\
\hline 9 & United Arab Emirates & 45 & Libya & 13 & Norway & 34 \\
\hline 10 & Norway & 44 & Singapore/Algeria/Indonesia & 12 & United Arab Emirates & 32 \\
\hline
\end{tabular}

(a) In - degree
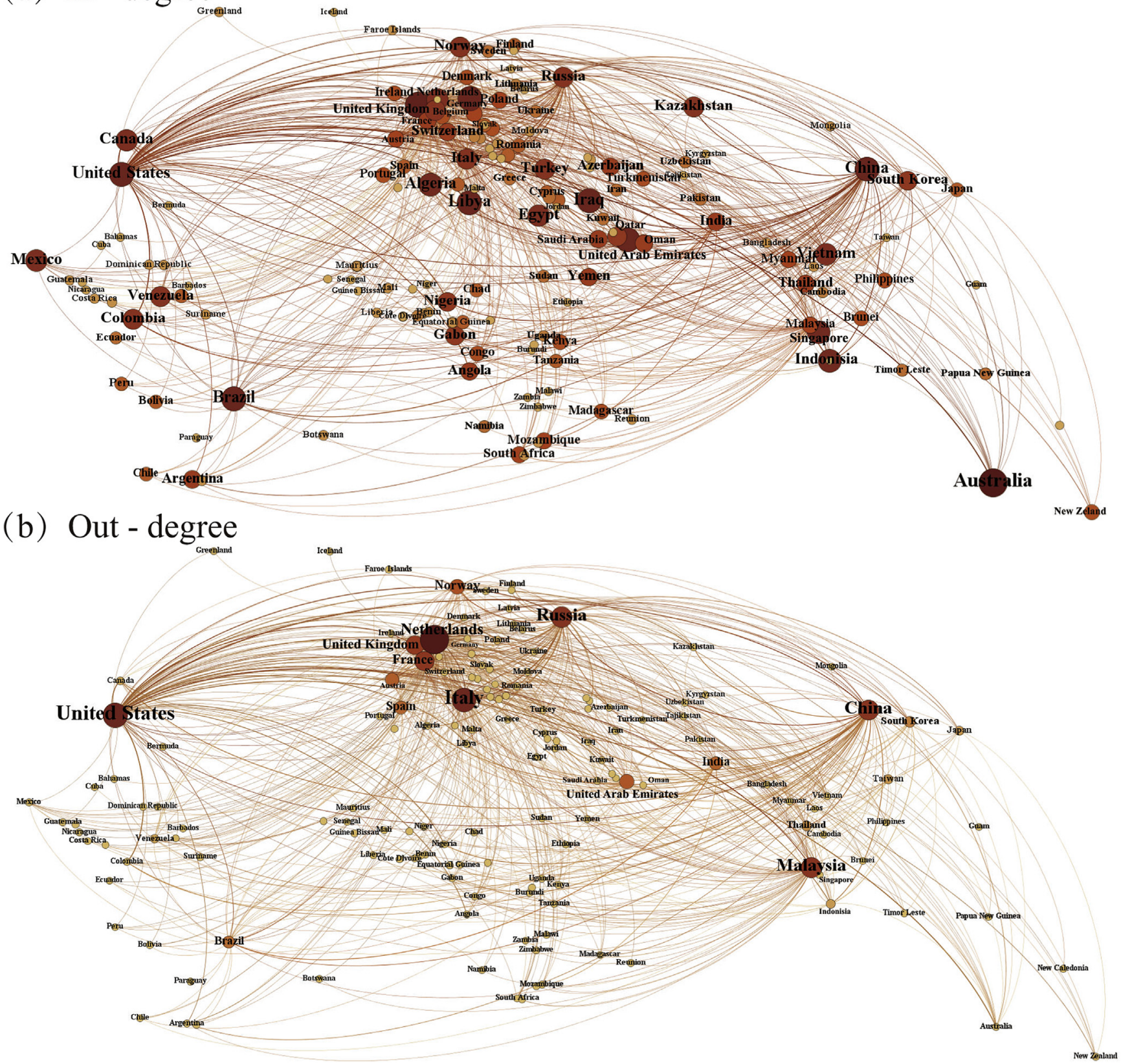

Fig. 2. In-degree (a) and out-degree (b) distributions of the global energy network. 
subsidiaries in the same countries to contend for resources or share the markets. Saudi Arabia and Russia are the most important suppliers in the global energy market, but both are absent from the indegree list. Some other producers, such as Iran, Kuwait, Nigeria and Angola, are also missing. Resource nationalism is the main contributing factor. These countries set restriction conditions for international investment, and reject most or even all of the investments in their upstream fields.

\subsection{Regional analysis}

To assist regional analysis, we have divided the world into five major regions: North America, Europe, South America, Asia and Oceania, and the Middle East and Africa. Countries within the Middle East and Africa are the main oil reserve areas, and few HQs are integrated here. The regional distribution of HQs and subsidiaries is shown in Table 3.

The European oil companies are likely to establish subsidiaries in Europe, which account for $39.17 \%$ of all their subsidiaries. Europe is an integrated region with excellent oil supply and demand markets. Oil-supplying countries include Russia, the United Kingdom, Norway, etc., while oil-demanding countries include Germany, France and most other European countries. The second subsidiary location of choice is the Middle East and Africa (25.83\%), which is the main overseas oil and gas destination and has an oil exploration history of hundreds of years since the Colonial Era. Following this is Asia and Oceania, which has a greater consumption market, including trade businesses, refineries, retail gas stations and other services.

For the North American companies, Asia and Oceania (30.08\%), Europe (27.07\%) and the Middle East and Africa (29.32\%) are the main destinations, with almost equal numbers of subsidiaries. Asian HQs have very different preferences toward setting up their overseas branches, most of which are located in the Middle East and Africa, as they seek upstream investment with huge energy demand. In addition, some will set up branches in North America and Europe because of their capital demand. The Middle East and Africa HQs appear to lack the strength of downstream capability to develop markets in Europe, North America and Asia; however, for capital requirement, Europe is an excellent choice (45.45\%).

With regard to the top ten transnational oil corporations, some significant differences can be identified. Their HHI indexes manifest diverse tendencies. The HHI indexes for Shell (0.24), Sinopec (0.25),
ExxonMobil (0.28), BP (0.31), Total (0.26), Chevron (0.28), ENI (0.28) and Petrobras (0.26) are close to each other and much lower than Gazprom (0.45) and CNPC (0.44). The former eight tend to be diversification while the latter two prefer to concentrate in specific areas. Shell is likely to set up subsidiaries in Europe, and the Middle East and Africa, but presents a widely dispersed status all over the world. Sinopec subsidiaries are mainly concentrated in the Middle East and Africa, and South America, while CNPC subsidiaries are mainly concentrated in Asia and Oceania, and the Middle East and Africa. ExxonMobil prefers Europe (36.36\%), and also Asia and Oceania. Europe and Asia are the most popular destinations for BP. Chevron shows great interest in Asia and Oceania (42.86\%). Total display great interest in the Middle East and Africa (40.00\%). ENY subsidiaries are mainly concentrated in Europe (32.37\%) and the Middle East and Africa (36.36\%). Gazprom, is the biggest national oil and gas company of Russia, which is seeking an energy diversification export strategy. It has many differences from other companies, which are seeking resources to ensure supply security. Gazprom focuses on the European markets (60.00\%) and also those in Asia and Oceania (28.89\%).

It is obvious that different transnational oil corporations have their own preferences for choosing the locations of their subsidiaries; these include their exploration history, their development strategy and the value chain of the upstream or downstream businesses they are pursuing. It is a remarkable fact that for political and historical reasons some host countries are only open to specific countries, while some host countries welcome all international investors. For example, Sudan has shown great enthusiasm for Chinese oil companies, Nigeria has appeared to maintain its long-term (hundreds of years) relationships with European companies and Kazakhstan has investors from more than 45 countries in its Tengiz, Kazakh, Karachagana oil fields, as well as in others.

\subsection{HQ subsidiary networks and trade networks}

The oil flow network contains records of the bilateral relationships between exports and imports with 149 nodes and 1074 edges, while the HQ subsidiary network contains 158 nodes and 918 edges. The scales of the two networks are therefore similar. We could employ the actual trade values to build weighted networks, which will better reflect actual oil flows; however, as a comparison study, we only calculate the unweighted networks for degree, indegree and out-degree of the HQ subsidiary network.

Table 3

Regional distributions of HQ subsidiaries.

\begin{tabular}{|c|c|c|c|c|c|c|c|c|c|c|c|}
\hline \multirow[t]{3}{*}{ HQs } & \multicolumn{11}{|c|}{ Subsidiaries } \\
\hline & \multicolumn{2}{|l|}{ Europe } & \multicolumn{2}{|c|}{ South America } & \multicolumn{2}{|c|}{ North America } & \multicolumn{2}{|c|}{ Asia and Oceania } & \multicolumn{2}{|c|}{$\begin{array}{l}\text { Middle East and } \\
\text { Africa }\end{array}$} & \multirow{2}{*}{$\begin{array}{l}\text { Total } \\
\text { Number }\end{array}$} \\
\hline & Number & Ratio & Number & Ratio & Number & Ratio & Number & Ratio & Number & Ratio & \\
\hline Europe & 188 & $39.17 \%$ & 34 & $7.08 \%$ & 36 & $7.50 \%$ & 98 & $20.42 \%$ & 124 & $25.83 \%$ & 480 \\
\hline South America & 7 & $24.14 \%$ & 8 & $27.59 \%$ & 3 & $10.34 \%$ & 4 & $13.79 \%$ & 7 & $24.14 \%$ & 29 \\
\hline North America & 36 & $27.07 \%$ & 11 & $8.27 \%$ & 7 & $5.26 \%$ & 40 & $30.08 \%$ & 39 & $29.32 \%$ & 133 \\
\hline Asia and Oceania & 25 & $10.29 \%$ & 20 & $8.23 \%$ & 15 & $6.17 \%$ & 78 & $32.10 \%$ & 105 & $43.21 \%$ & 243 \\
\hline Middle East and Africa & 15 & $45.45 \%$ & 4 & $12.12 \%$ & 2 & $6.06 \%$ & 5 & $15.15 \%$ & 7 & $21.21 \%$ & 33 \\
\hline Shell & 28 & $28.87 \%$ & 8 & $8.25 \%$ & 12 & $12.37 \%$ & 18 & $18.56 \%$ & 31 & $31.96 \%$ & 97 \\
\hline Sinopec & 2 & $9.52 \%$ & 5 & $23.81 \%$ & 3 & $14.29 \%$ & 3 & $14.29 \%$ & 8 & $38.10 \%$ & 21 \\
\hline CNPC & 2 & $9.09 \%$ & 0 & $0.00 \%$ & 0 & $0.00 \%$ & 8 & $36.36 \%$ & 12 & $54.55 \%$ & 22 \\
\hline ExxonMobil & 20 & $36.36 \%$ & 3 & $5.45 \%$ & 3 & $5.45 \%$ & 16 & $29.09 \%$ & 13 & $23.64 \%$ & 55 \\
\hline $\mathrm{BP}$ & 22 & $42.31 \%$ & 1 & $1.92 \%$ & 4 & $7.69 \%$ & 15 & $28.85 \%$ & 10 & $19.23 \%$ & 52 \\
\hline Total & 11 & $20.00 \%$ & 6 & $10.91 \%$ & 4 & $7.27 \%$ & 12 & $21.82 \%$ & 22 & $40.00 \%$ & 55 \\
\hline Chevron & 8 & $22.86 \%$ & 4 & $11.43 \%$ & 2 & $5.71 \%$ & 15 & $42.86 \%$ & 6 & $17.14 \%$ & 35 \\
\hline Gazprom & 27 & $60.00 \%$ & 2 & $4.44 \%$ & 0 & $0.00 \%$ & 13 & $28.89 \%$ & 3 & $6.67 \%$ & 45 \\
\hline ENI & 25 & $32.47 \%$ & 6 & $7.79 \%$ & 3 & $3.90 \%$ & 15 & $19.48 \%$ & 28 & $36.36 \%$ & 77 \\
\hline Petrobras & 3 & $13.04 \%$ & 8 & $34.78 \%$ & 2 & $8.70 \%$ & 3 & $13.04 \%$ & 7 & $30.43 \%$ & 23 \\
\hline
\end{tabular}


We present the oil trade network based on Fig. 3. With regard to the degree of the top ten ranked countries (Table 4), most of the countries in the trade network are more or less the same as the HQ subsidiary network. Italy, Malaysia, Norway and Brazil, who had degrees of 85, 66, 44 and 36 in the HQ subsidiary networks, are absent in the trade networks, while Canada, Germany, South Korea and Singapore do not appear in the HQ subsidiary network, yet are present in the trade network. This phenomenon indicates that some countries are powerful operators in the global energy business, and they do not need much oil trade. Other countries are heavily dependent on overseas energy and are not powerful operators in the energy business and rely to some extent on trade relationships other than international branches.

In the trade network, the in-degree and out-degree indexes are significantly different from those in the HQ subsidiary network (see also Table 4). Compared to the rather unbalanced concentration and dispersion of HQ subsidiary network, the in-degree and out-degree of trade networks show a similar status with the HHIs both approximating to 0.02 . Top of the list for the in-degrees of the trade network are most of the countries that need many oil importers, while the HQ subsidiary network countries like foreign direct investments in both the energy demanders and the suppliers. Top of the list for the out-degrees of the HQ subsidiary network are the countries that own powerful global operating companies with huge capital, while top of the list for the trade network are oil suppliers with abundant energy-producing capacities (Russia, United States, United Kingdom, six Middle East and North Africa countries and one Central Asia country).

In Fig. 4, we have drawn Lorenz curves that show the inequality of the two networks. The trade network is more equality $($ Gini $=0.53)$ than the HQ subsidiary network (Gini $=0.65)$ according to the Gini coefficient. This indicates that the trade relationships are more dispersed and more balanced. There are obvious differences in the Gini coefficient between the in-degree and out-degree. The trade network is more balanced between indegree and out-degree, with Gini coefficients equal to 0.66 and 0.62 , respectively, compared to the Gini coefficients of the HQ subsidiary network, which is equal to 0.42 and 0.91 for the indegree and out-degree, respectively. This indicates that the distributions of export and import relationships are similar, while the distributions of investments are rather uneven.

In Fig. $4 \mathrm{~A}-\mathrm{b}$ and A-c, the in-degree Lorenz curve is smoother than the out-degree Lorenz curve. The HQs are from very few countries, while most investments are widely separated into oilproducing countries and consumption countries throughout the world. Lorenz curves of oil trade network in Fig. 4 B-b and B-c show similar trends with in-degree Gini and out-degree Gini. The trade network is mainly reflected by the demanders and suppliers, which have a balanced commodity network with many relationships on both the import and export side. The HQ subsidiary network includes trade companies, exploration companies, research and development departments, capital centers and marketing departments, which means a more comprehensive network driven by power from the hubs. The locational distribution of oil companies and their facilities is strong evidence to explain the spatial unevenness and inequality of the oil trade.

\subsection{IOC networks and NOC networks}

IOCs, which can be traced back to the "Seven Sisters", controlled around 85\% of the world's oil reserves before the oil crisis in 1973 . Now, although IOCs are losing their dominant status in reserves, they are still the most important organizations influencing the world energy market because of their wide networks of investments, huge assets, advanced technologies and irreplaceable global marketing operations. After many mergers and reorganizations, the super majors in today's energy market are considered to be BP plc, Chevron Corporation, ExxonMobil Corporation, Royal Dutch Shell plc and Total SA (Antill \& Arnott, 2002). NOCs are fully or mostly operated by national governments, and show the "national purpose" to some extent other than pursuing profits. Owing to their powerful government financial and political support, NOCs have started to organize their overseas businesses from upstream to downstream, and are forming their own energy

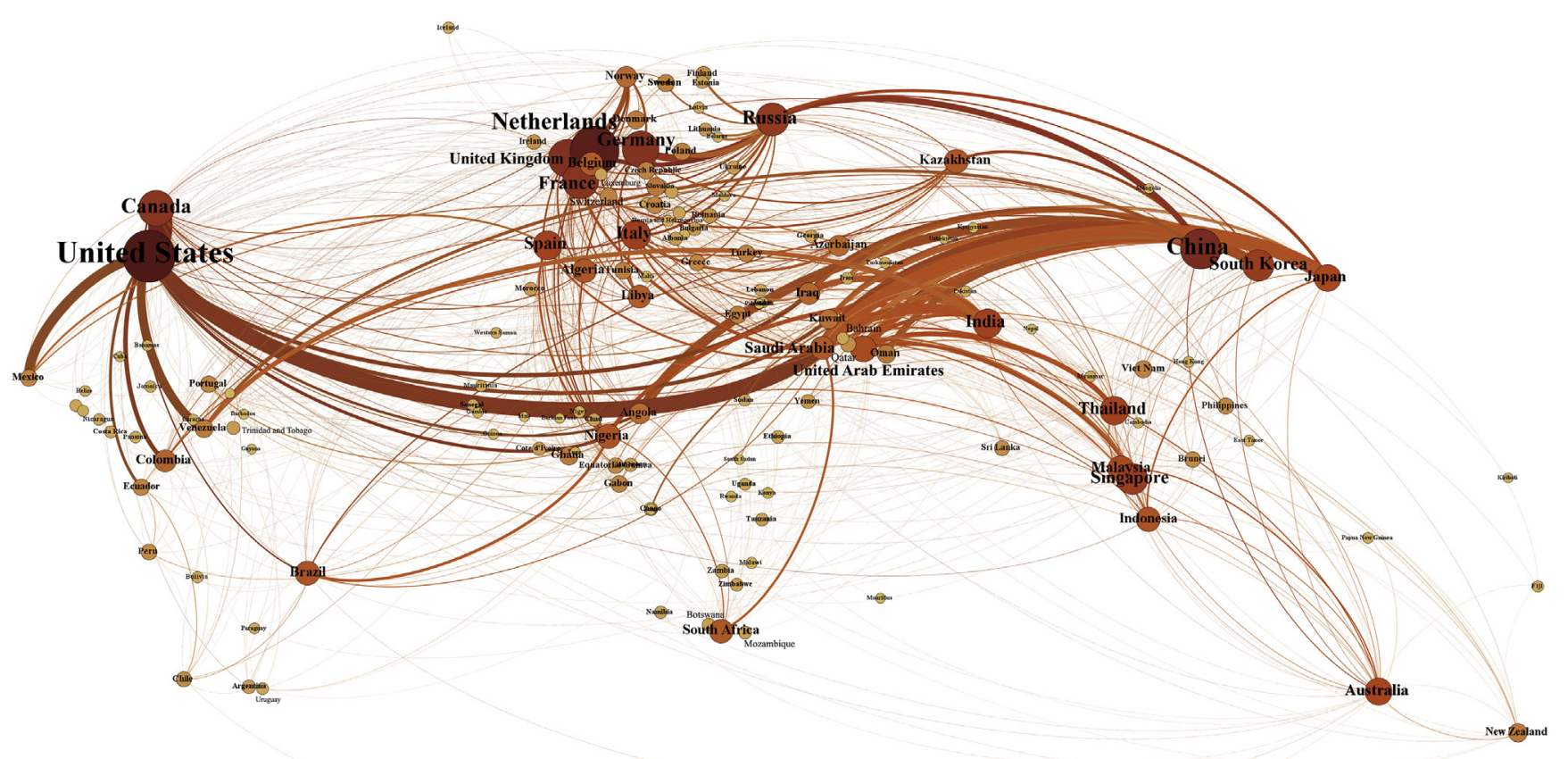

Fig. 3. Degree distribution of the global oil trade network (2013). Note: Node size captures k size while thickness of lines indicates reality trade. 
Table 4

Degree, in-degree and out-degree of top ten ranked countries in trade network.

\begin{tabular}{|c|c|c|c|c|c|c|}
\hline \multirow[t]{2}{*}{ Rank } & \multicolumn{2}{|l|}{ Degree (k) } & \multicolumn{2}{|l|}{ In-degree $\left(\mathrm{k}_{\mathrm{in}}\right)$} & \multicolumn{2}{|l|}{ Out-degree $\left(\mathrm{k}_{\text {out }}\right)$} \\
\hline & Country & Value & Country & Value & Country & Value \\
\hline 1 & United States & 90 & Netherlands & 60 & United States & 48 \\
\hline 2 & Netherlands & 83 & China & 45 & Russia & 47 \\
\hline 3 & China & 65 & United States & 42 & United Kingdom & 37 \\
\hline 4 & United Kingdom & 59 & Canada & 40 & United Arab Emirates & 35 \\
\hline 5 & Canada & 57 & South Korea & 40 & Nigeria & 31 \\
\hline 6 & Germany & 57 & France & 37 & Saudi Arabia & 29 \\
\hline 7 & France & 56 & Singapore & 36 & Kazakhstan & 28 \\
\hline 8 & Russia & 49 & Spain & 35 & Libya & 28 \\
\hline 9 & South Korea & 46 & India & 34 & Algeria & 25 \\
\hline 10 & Singapore & 45 & Thailand & 34 & Iraq & 25 \\
\hline
\end{tabular}

HQ subsidiary network

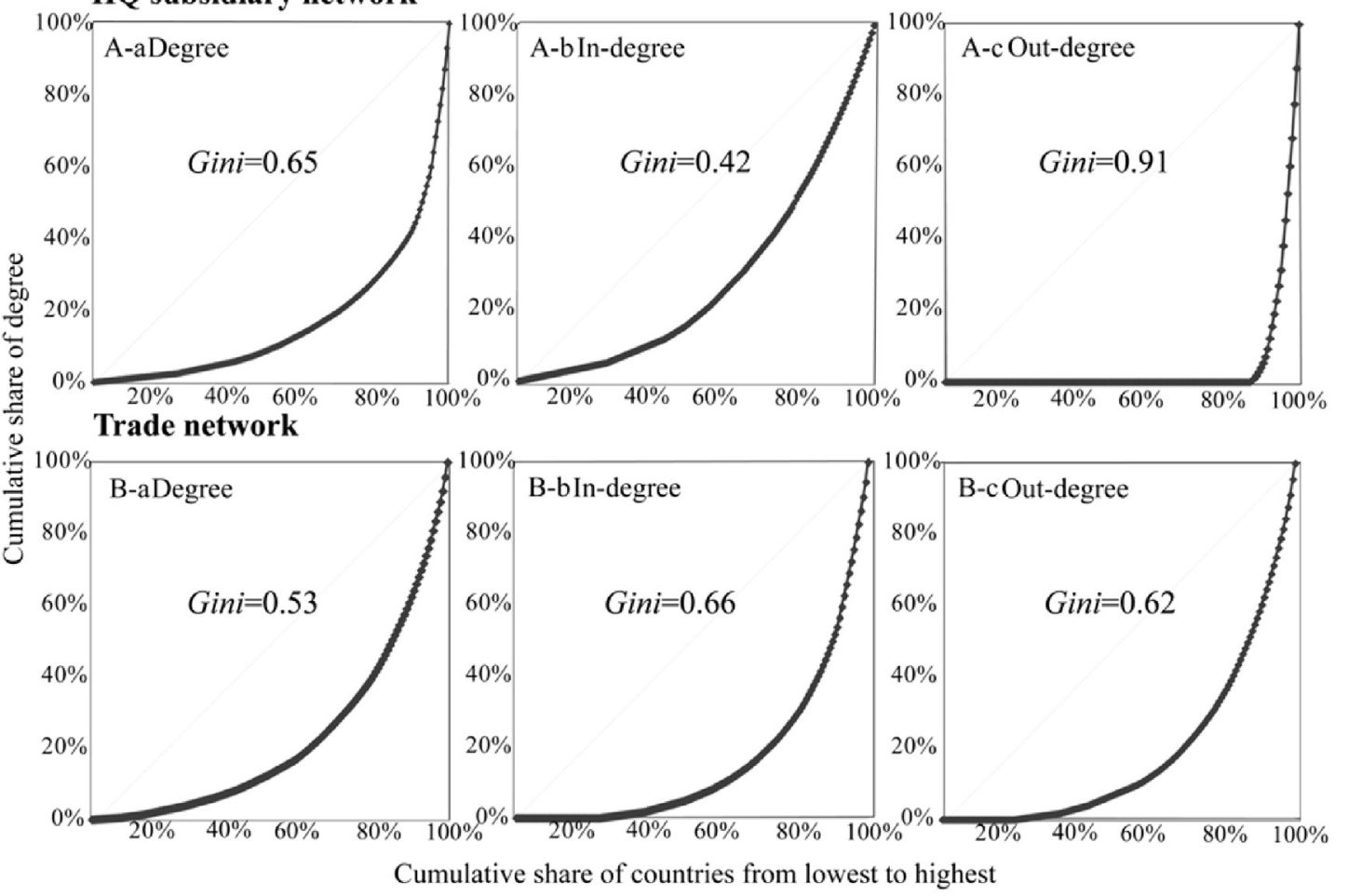

Fig. 4. Lorenz curves and Gini coefficients of the two networks.

networks. However, compared to other companies, they suffer from a lack of competition and have been criticized as ineffective and inefficient (Lewis, 2007; Tordo, Tracy, 2011).

It is obvious that IOCs and NOCs have significantly different types of network. We take BP and ExxonMobil as examples of IOCs, and PETRONAS and CNPC as examples of NOCs, in order to analyze their differences (Fig. 5). IOCs are mostly multinational companies with diversified products that cover many fields. Their energy networks are complicated integrations with subsidiaries in different value chains. Generally speaking, with regard to BP and ExxonMobil, which are very representative, the upstream businesses of IOCs are mostly resource-based, and the downstream businesses are mostly market-based. They operate exploration and development projects in oil producing countries and then refine and process close to the markets. NOCs networks are mainly resources-based and are focused on the upstream.

BP has set up subsidiaries in 52 countries according to our data, while according to BP annual reports BP had operations in more than 80 countries. As can be seen in Fig. 5a, the BP upstream is distributed in 27 countries, with a high concentration in Canada, North Africa, the North Sea, Azerbaijan and the Middle East. The BP downstream segment focuses on fuels, lubricants and petrochemicals. BP has significant markets in Europe, North America and Asia, while it also manufactures its products across the Atlantic and Pacific in America, Africa and Australia. The refinery subsidiaries are mostly in Europe and the United States and its petrochemical sites prosper in China. Alternative energy assets and technology assets are in the United States, United Kingdom and Brazil.

ExxonMobil, the third largest oil company, has also set up hundreds of overseas subsidiaries, among which we counted overseas subsidiaries distributed in 55 countries. The ExxonMobil upstream businesses have an exploration or production presence in 39 countries and cover all resource types and geographies. They are widely spread in North and South America, West Africa, Western Europe, Gulf Area, Asia and even Russia. ExxonMobil organizes its refinery in facilities in 17 countries. The downstream businesses of ExxonMobil are mainly distributed in North America, Western Europe and Asia-Pacific. Additionally, ExxonMobil Chemical has 
(a) $\mathrm{BP}$
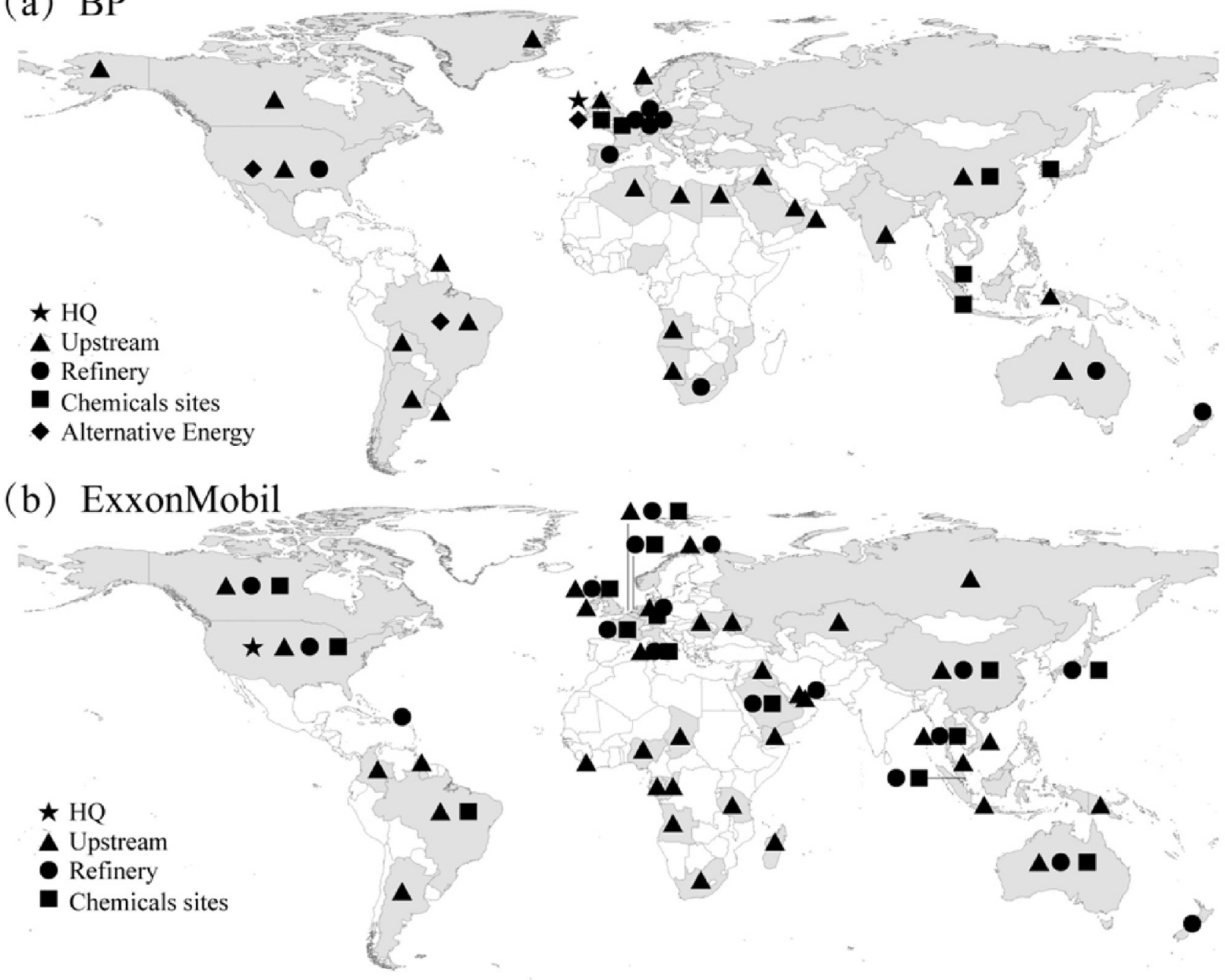

(c) CNPC

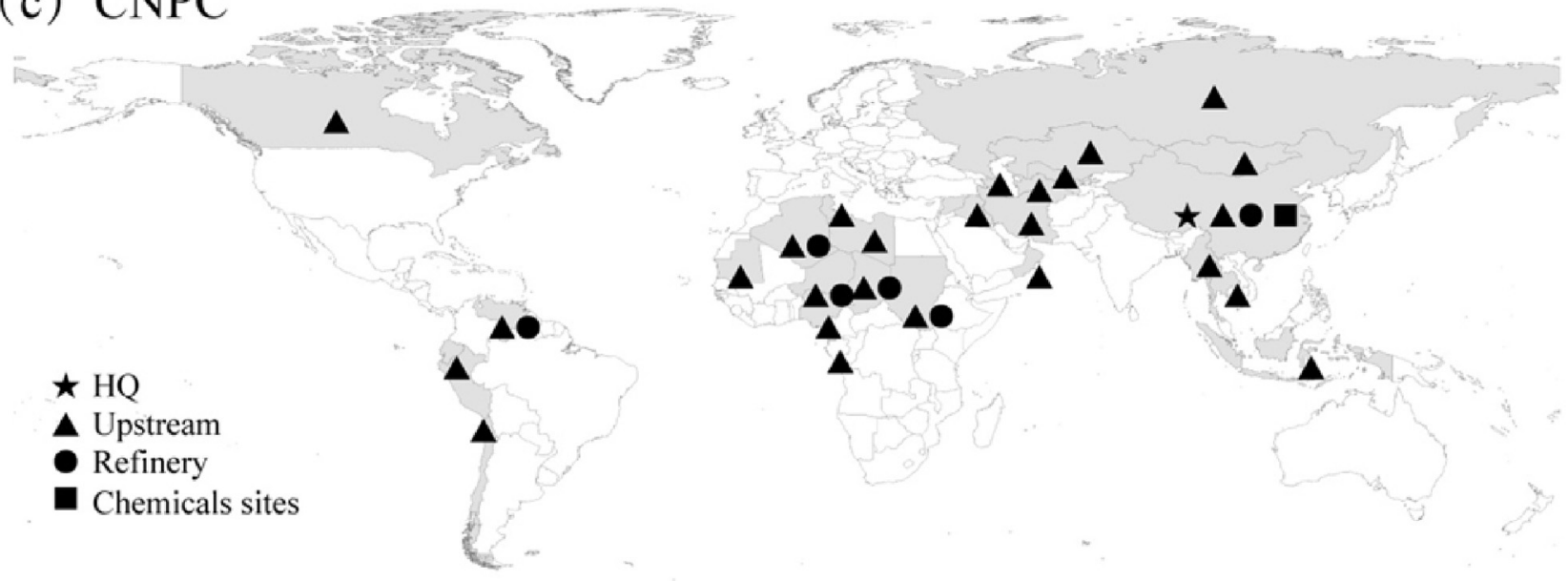

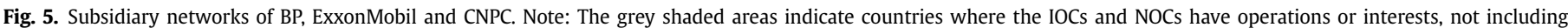
trading and marketing offices.

set up manufacturing subsidiaries in 15 countries: Canada, United States, Brazil, United Kingdom, France, Italy, Germany, Netherlands, Belgium, Saudi Arabia, China, Japan, Thailand, Singapore and Australia.

PETRONAS is a Malaysian oil and gas company, which has formed its own networks from upstream to downstream businesses not only in Malaysia but also in the global market. PETRONAS operates exploration and production businesses in about 20 countries, most of which are concentrated in Africa and Southeast Asia; there are also a few projects in Central Asia, the Middle East, 
Latin America and Canada. PETRONAS has regional gas and power networks mainly in Asia-Pacific, including Australia, Indonesia, Malaysia, Singapore, Thailand and other dispersed areas. The downstream businesses are mostly oil and lubricants, and are widely distributed in Africa, Asia-Pacific and Europe. PETRONAS has 21 downstream subsidiaries in Africa, seven downstream subsidiaries in Asia-Pacific and 13 in Europe; others are in Latin America, the Middle East and North America. According to the company's 2013 annual report, the downstream businesses are mostly marketing and trading offices. The subsidiary network map is not reproduced here owing to copyright restrictions.

CNPC is an oil enterprise operated by China's central government. From the early 2000s, CNPC start to achieve its ambitions with the aid of China's powerful financial and diplomatic support. CNPC now has subsidiaries and assets in more than 20 countries. The international expansion of CNPC is often criticized as the Chinese central government's approach to enhancing China's oil supply security. Unlike major IOCs, CNPC, as a relative latecomer to the international market, has less capability of controlling varieties of risks simultaneously and had little choice but to take what it could get. Many of the assets purchased by CNPC were not especially attractive to the IOCs. Compared to IOCs, the reserves of CNPC are highly concentrated in some countries with elevated levels of political risk. Also, lack of advanced technology has limited CNPC to competing for the most attractive deepwater oilfields in South America (Brazil) and Africa (Angola and Nigeria). As can be seen from Fig. $5 c$, the overseas subsidiaries are mainly concentrated in South Asia, Central Asia, North Africa, Canada and Russia. Most of the subsidiaries are in upstream, exploration and oilfield technical services businesses. Only a few projects are related to downstream industries, such as an integrated program in Africa.

\section{Conclusions and policy implications}

By applying scale-free network analysis to the HQ subsidiary network, this paper has discovered that Netherlands, United States, Italy, Russia, United Kingdom, China, Malaysia, France, United Arab Emirates and Norway are the most important cores in order to construct a framework of global energy networks, owing to their powerful transnational corporations. Oil company HQs are concentrated in North America, Western Europe and East and Southeast Asia, which are the three biggest markets, have a great deal of capital and have huge energy consumptions. The subsidiaries are distributed around the world, with producing countries in the Persian Gulf, South America, North Africa and Central Asia, and consumption countries in North America, Europe and East Asia. Australia, United Kingdom, United States, China, United Arab Emirates, Brazil, Germany, Iraq, Libya, Singapore, Algeria and Indonesia are the most popular countries to set up subsidiaries. However, Saudi Arabia and Russia, the two most important oil and gas suppliers, do not open their resource markets to international investors in keeping with their national resource policies. This is rather different to crude oil trade networks, which take the OPEC oil-producing countries and other important producers as cores. Compared to the trade network, the HQ subsidiary network displays greater inequality, especially in the out-degree network.

Different oil companies have their own preferences for choosing the locations of their subsidiaries according to their different oil exploration histories, their development strategies and the upstream or downstream industries they are pursuing. IOCs are vertically integrated companies operating in whole value chains of the oil and gas industry. They set up subsidiaries by considering the structural balance between upstream and downstream businesses. Some NOCs seek acquisition of exploration and production assets abroad. Downstream industries are mostly concentrated in their own mainland countries. Compared to IOCs, most NOCs lack advanced exploration and production capacity, and also lack the ability to assess risks. However, they build their global energy asset networks with high financial support from their central governments.

It is undeniable that the energy HQ subsidiary network is more complex, as it relates to every field of the oil and gas industry. The network combines benefits of the companies, developing government proposals, global oil trade, technology development and even geopolitics and wars. HQ-subsidiary energy network should be seriously considered along with the international diplomatic relations when making transnational energy policies and trading. It has great influence on current energy networks which based on the trading relationships and diplomatic relationships. As dependent or independent powerful international actors, both IOCs and NOCs should be responsible for more balanced and "win-win" networks. Competition and cooperation are the norms. Better cooperation is the main direction to develop a better network in the future.

IOCs are losing their dominance of oil reserves and are not welcome to invest in some producing countries due to their lower returns to local economies. IOCs must build better relationships with the NOCs in order to gain access to upstream fields as well as access to rising markets in developing countries. Also, IOCs have been criticized for their shrewd investments in high-quality oil fields, and are not interested in locations where there are serious technical conditions requiring huge capital investments. They even withdraw capital from deteriorating fields. Although choosing whichever is to one's advantage is a kind of economic rule, oil exploration appears to be more sensitive to national benefits.

NOCs are also responsible for contributing to a more equitable market order without depending on the power of the government, which is unfair toward efficient market evolution. Returning to an economic-dominated market rather than obtaining acquisitions by international political influence or political exchange is an irreversible trend. Cooperating with the IOCs is a positive method for achieving advanced technology and management experience, which can offset the NOCs' lack of risk estimates. A more integrated energy cooperation network between the powerful actors will greatly decrease the instability of energy geopolitics. Cooperation between CNPC and Gazprom is a good attempt. CNPC and Gazprom signed a memorandum of understanding in upstream and downstream cooperation and established the Eastern Petrochemical Company. CNPC obtained permission to enter the upstream filed of Russia under the cooperation framework, while Gazprom got the authorization from the Chinese government to establish gas stations in North China.

For further studies, weighted networks with subsidiary scales and values would be better and will be more close to the reality. However, the data are very difficult to obtain. It is worth noting that, more detailed data will be needed to identify the different kinds of relationships between HQs and subsidiaries in future research. For example, there are some countries that export their crude oil to other countries just for the purpose of refining because they lack indigenous refinery capacity. The HQs and subsidiaries setting for such relationships should be considered separately. What's more, relationships under different subsidiary functions should be distinguished. In addition, renewable energy trade is booming and becoming an important part of the international energy trade. Renewable energy companies and their subsidiaries are forming their own networks beyond traditional energy networks. Future studies should be focused on such things and pay attention to the differences between traditional energy networks and renewable energy networks. 


\section{Acknowledgements}

\section{Support from the National Natural Science Foundation of China under Grant No. 41401132, No. 41371141 and No.41430636 is} acknowledged.

\section{References}

Alhajji, A. F., \& Huettner, D. (2000a). OPEC and other commodity cartels: a comparison. Energy Policy, 28(15), 1151-1164.

Alhajji, A. F., \& Huettner, D. (2000b). OPEC and world crude oil markets from 1973 to 1994: cartel, oligopoly, or competitive? Energy Journal, 21(3), 31-60.

Antill, A., \& Arnott, R. (2002). Oil company crisis: Managing structure, profitability and growth. Oxford Institute for Enegy Studies.

An, H. Z., Zhong, W. Q., Chen, Y. R., Li, H. J., \& Gao, X. Y. (2014). Features and evolution of international crude oil trade relationships: a trading-based network analysis. Energy, 74, 254-259.

Barigozzi, M., Fagiolo, G., \& Garlaschelli, D. (2010). Multinetwork of international trade: a commodity-specific analysis. Physical Review E, 81(4), 1-23.

Benenson, I., Sofer, M., \& Schnell, I. (1998). Analysis of economic networks: geographical information systems as a visualization tool. Applied Geography, 18(2), 117-135.

Bin, H. (2014). Oil and gas cooperation between China and Central Asia in an environment of political and resource competition. Petroleum Science, 11(4), $596-605$.

Blum, H., \& Legey, L. F. L. (2012). The challenging economics of energy security: ensuring energy benefits in support to sustainable development. Energy Economics, 34(6), 1982-1989.

Boussena, S., \& Locatelli, C. (2013). Energy institutional and organisational changes in EU and Russia: revisiting gas relations. Energy Policy, 55, 180-189.

Bremond, V., Hache, E., \& Mignon, V. (2012). Does OPEC still exist as a cartel? an empirical investigation. Energy Economics, 34(1), 125-131.

Cairns, R. D., \& Calfucura, E. (2012). OPEC: market failure or power failure? Energy Policy, 50, 570-580.

Casertano, S. (2013). International oil companies in the post-studio era: strategic responses of energy majors to the 2003-2008 price boom. Energy Strategy Reviews, 1(3), 211-217.

Costa, L. D., Rodrigues, F. A., Travieso, G., \& Boas, P. R. V. (2007). Characterization of complex networks: a survey of measurements. Advances in Physics, 56(1), $167-242$.

Dike, J. C. (2013). Measuring the security of energy exports demand in OPEC economies. Energy Policy, 60, 594-600.

Feng, G., \& Mu, X. (2010). Cultural challenges to Chinese oil companies in Africa and their strategies. Energy Policy, 38(11), 7250-7256.

Frynas, J. G., \& Paulo, M. (2007). A new scramble for African oil? Historical, political, and business perspectives. African Affairs, 106(423), 229-251.

Geng, J. B., Ji, Q., \& Fan, Y. (2014). A dynamic analysis on global natural gas trade network. Applied Energy, 132, 23-33.

Hartley, P., \& Medlock, K. B. (2008). A model of the operation and development of a national oil company. Energy Economics, 30(5), 2459-2485.

Hartley, P. R., \& Medlock, K. B. (2013). Changes in the operational efficiency of national oil companies. Energy Journal, 34(2), 27-57.

Ji, Q., Zhang, H. Y., \& Fan, Y. (2014). Identification of global oil trade patterns: an empirical research based on complex network theory. Energy Conversion and Management, 85, 856-865.

Kaufmann, R. K. (2004). Does OPEC matter? an econometric analysis of oil prices.
Energy Journal, 25(4), 67-90.

Knapp, D. (2004). Oil company crisis: managing structure, profitability, and growth. Energy Journal, 25(1), 109-111.

Leverett, F., \& Bader, J. (2005). Managing China-US energy competition in the Middle East. Washington Quarterly, 29(1), 187-201.

Lewis, S. W. (2007). Chinese NOCs and world energy markets: CNPC, SINOPEC and CNOOC. Houston: Rice University.

Mann, J. (2009). Russia's policy towards OPEC. Middle Eastern Studies, 45(6), 985-1005.

McGregor, J. R. (1979). Evolution of OPEC strategy. Annals of Regional Science, 13(2), $152-153$.

Ngoasong, M. Z. (2014). How international oil and gas companies respond to local content policies in petroleum-producing developing countries: a narrative enquiry. Energy Policy, 73, 471-479.

Palazuelos, E. (2010). The role of transnational companies as oil suppliers to the United States. Energy Policy, 38(8), 4064-4075.

Palazuelos, E., \& Fernández, R. (2012). The importance of transnational corporations in the supply of oil to Europe: Implications. Energy Policy, 47, 270-281.

Pegg, S. (2012). Social responsibility and resource extraction: are Chinese oil companies different? Resources Policy, 37(2), 160-167.

Pirog, R. (2012). Financial performance of the major oil companies, 2007-2011. CRS Report for Congress.

Poon, J., Kedron, P. \& Bagchi-Sen, S. (2013). Do foreign subsidiaries innovate and perform better in a cluster? A spatial analysis of Japanese subsidiaries in the US. Applied Geography, 44, 33-42.

Scott, J. (2000). Social network analysis: A handbook (2nd ed.). London: SAGE Publications Ltd.

Singleton, A. D., \& Longley, P. A. (2009). Geodemographics, visualisation, and socia networks in applied geography. Applied Geography, 29(3), 289-298.

Stevens, P. (2008). National oil companies and international oil companies in the Middle East: under the shadow of government and the resource nationalism cycle. Journal of World Energy Law \& Business, 1(1), 5-30.

Tordo, S., Tracy, B. S., \& Arfaa, N. (2011). National oil companies and value creation. World Bank Working Paper No, 218, 1-132.

Tordo, S., Tracy, S., \& Arfaa, N. (2011). National oil companies and value creation. Wahington DC.

Venouss, D., Walter, C. K., \& Thompson, A. F. (1984). OPEC goal and strategies. International Journal of Middle East Studies, 16(2), 199-206.

Vivoda, V. (2009). Diversification of oil import sources and energy security: a key strategy or an elusive objective? Energy Policy, 37(11), 4615-4623.

Wasserma, S., \& Faust, K. (1994). Social network analysis: methods and application (structural analysis in the social sciences). New York: Cambridge University Press.

Watkins, E. (2009). Russia declines OPEC membership; offers alternative. Oil and Gas Journal, 107(12), 24-25.

Yang, Y., Poon, J., Liu, Y., \& Sharmistha, B. (2015). Small and flat worlds: a complex network analysis of international trade in crude oil. Energy, 93(P1), 534-543.

Yergin, D. (2006). Ensuring energy security. Foreign Affairs, 85(2), 69-82.

Zhang, Z. (2012). The overseas acquisitions and equity oil shares of Chinese nationa oil companies: a threat to the West but a boost to China's energy security? Energy Policy, 48, 698-701.

Zhang, H. Y., Ji, Q., \& Fan, Y. (2013). An evaluation framework for oil import security based on the supply chain with a case study focused on China. Energy Economics, 38, 87-95.

Zhang, H. Y., Ji, Q., \& Fan, Y. (2014). Competition, transmission and pattern evolution: a network analysis of global oil trade. Energy Policy, 73, 312-322.

Zhong, W. Q., An, H. Z., Gao, X. Y., \& Sun, X. Q. (2014). The evolution of communities in the international oil trade network. Physica A-Statistical Mechanics and Its Applications, 413, 42-52. 